\title{
A Study on the Drivers of Employee Engagement and its Relationship with Employee Performance
}

\author{
Syeda Nazneen Waseem * $\quad$ Kashif Mehmood ${ }^{\dagger}$
}

\begin{abstract}
The statement claiming that the raised employees' engagement level will eventually help increase the employees' well-being and work performance has not previously vastly tested, specifically within faculty members of higher educational institutions (HEIs). The scarcity of noteworthy studies on the antecedents and outcomes of employee engagement is addressed while a complete, holistic and comprehensive model is presented in the paper that presents a rational basis on which further testing of the hypotheses could be identified and tested to verify the theory. Based on the job demands resources model (JDR), it is hypothesized in the current study that work engagement would be influenced by job resources and also engagement in turn have a positive impact on employees in role and extra role performance behaviors. We used a non-experimental design study with a survey sample of $N=189$ permanent full time teachers participated in the study. Structural equation modeling were applied to test the model empirically, the results showed that only one job resource out of three had a positive significant effect on boosting work engagement. Additionally, the employee engagement at workplace was also found positively and significantly influencing employees' self rated performance. The current study also discussed the implications of these findings with respect to theory and practice.
\end{abstract}

Keywords: Employee engagement, job resources, employee performance, higher educational institutions (HEIs).

\section{Introduction}

In this contemporary world across globe especially after the start of 21st century, not only organizational structures are evolving rapidly but the transformation in the workforce is observed due to due to demographic shifts (Waseem, Frooghi, \& Khan, 2016) and workforce diversity (Yadav \& Katiyar, 2017). Today in order for the companies to grow they have realized the importance of talent management as the secret to their growth (Cappelli \& Keller, 2017), therefore human resource are the only strategic resource to capitalize upon. Organization today focus on and utilize engaged employees as its strategic partner for being competitive in the business world (Bedarkar \& Pandita, 2014) as the scholars realized that those employees who respond at work with improved level of energy, greater enthusiasm, are able to cope up with hardships and also while working time flies for them are

\footnotetext{
*PhD Scholar, IQRA University Lecturer, Karachi University Business School.

E-mail: nazneen.waseem@uok.edu.pk

†Associate Professor, IQRA University. Communication from UUM, Malaysia. E-mail: drkashif@iqra.edu.pk
} 
actually regarded as engaged employees (Schaufeli \& Bakker, 2004). Therefore, employee engagement because of its significance has received increased attention of researchers' in academic, business practitioners, and at governmental level (Yalabik, Popaitoon, Chowne, \& Rayton, 2013; Waseem et al., 2016). This highlights the importance and responsibility of employing enterprises to provide a supportive culture to their employees where they can remain committed and highly engaged with their jobs (Storm \& Rothmann, 2003; Bailey, Madden, Alfes, \& Fletcher, 2017).

The construct of employee engagement is although not new but is definitely is the one that required clarification vis-a-vis other work related existing constructs (Macey \& Schneider, 2008; Hallberg \& Schaufeli, 2006) and its theoretical conceptualizations (Shuck \& Wollard, 2010). It is more than 25 years since Kahn wrote first time about 'personal engagement' with work, discussing if the employees opt to invest and engross themselves fully and authentically in their working roles. Crawford, Rich, Buckman, and Bergeron (2013); Macey and Schneider (2008) wrote that since then there has been a mushroom growth in the development of a baffling multiplicity of definitions, measures, theories and conceptualizations of employee engagement. Study on workplace engagement is not only receiving interest of the researcher but is also becoming a buzzword which is being considered as HRM's new best friend in the recent era (Williams \& Anderson, 1991). Literature defines Work engagement as a "positive, fulfilling, work-related state of mind that is characterized by vigor, dedication, and absorption" (Schaufeli, Salanova, González-Romá, \& Bakker, 2002). Vigor has been referred to high levels of energy, mental resistance, a willingness to put effort into one's work and tenacity even in the time of difficulties (Schaufeli et al., 2002). Dedication is referred to "a sense of significance, enthusiasm, inspiration, pride and challenge" in one's job that is being performed (Schaufeli et al., 2002). Absorption is elaborated as the extent to which an employee is fully focused and deeply gripped in his or her work. There are six main distinct streams categorized as engagement conceptualizations, but in the literature most dominant conceptualization which is well studied is construct and measure of Utrecht Group's 'work engagement', and in terms of theorization the 'job demands-resources' framework is mostly studied (Bailey et al., 2017) . Thus, the JD-R model helps explaining 'engagement' with the principle of; as those employees are more likely to demonstrate high engagement at their work with high levels of job and/or personal resources (Albrecht \& Marty, 2017; Bailey et al., 2017).

The connection among different work attachment related constructs has been investigated by numerous researchers and scholars of western countries, also work engagement with its impact on employee performance within various contexts and particularly human services, but none has studied the integrated framework of the antecedents as drivers of engagement and their impact on employee in role and extra role performances together within Higher Education sector of Karachi, Pakistan. Waseem, Frooghi, and Afshan (2013) wrote in order to eradicate poverty and for the society to progress socially and economically education is the only most powerful instrument which ultimately develops responsible citizens too. The role of HEIs/Universities for shaping the future strengths and socio economic development of any country can't be underestimated, objectives of universities are to build and accommodate literate economy (Parakhina, Godina, Boris, \& Ushvitsky, 2017). Education is considered as a vital investment for the socio-economic progress of a country. 
To help develop knowledge and skills based economies education and educationist play an important role. The employees of the education sector can mark an important difference and with a dominant influence on the results of organization (Van Wingerden, Derks, \& Bakker, 2017). Therefore, the focus of this study is to establish relationship of engagement vis performance of the faculty of HEIs, to establish the external validity of the previous researches on engagement and address the lack of academic literature on the antecedents and outcome of engagement (Bailey et al., 2017).

Although various researches (Bakker \& Demerouti, 2007; Bailey et al., 2017) has previously examined interactions among different personal and job-related factors as antecedents of work engagement. The combine research on work engagement and performance based outcome is relatively new (Mone \& London, 2018). Performance management helps employers to direct and focus their employees' efforts but sometimes even currently highly engaged employees, can experience burnout (Waseem et al., 2016; Mone \& London, 2018).

\section{Literature Review}

\section{Theoretical Background}

The present study based on three models and other relevant theories combine to examine their impact on employee performance. Previously many studies have strived to explain engagement and employee performance but few of the models explained the phenomenon with the integrative approach (Mone \& London, 2018) but none within Pakistani context. Employee performance regarded as the eventual target of the management of any organization shall need to be studied broadly so that the company's image and productivity can be enhanced (Frooghi \& andSyeda NazneenWaseem, 2016); in line with it the current study has integrated the Job Demand Resource Model-JDR (Bakker \& Demerouti, 2008), Social exchange theory and Engagement model by Saks (2006) combine to predict the employees performance outcome of any organization leading ultimately to customers satisfaction which is the most dominant desire of any service oriented sector company. In a recent study was concluded that intervention of job resources at work will ultimately enhance the level of work engagement and thus improved performance (Van Wingerden et al., 2017). This current study aims to enrich the scant literature by first time integrating three models and the relevant theories to help explain engagement vis performance in one of the most important sector of the country that is education industry, especially within Pakistani context.

\section{Empirical Studies}

\section{Employee Engagement}

The concept of 'personal engagement' was first conceptualized by W.A. Kahn, who is regarded as an academic parent of the engagement movement (Bedarkar \& Pandita, 2014), for individual roles 'as the extent to which an individual is psychologically existent in a certain organizational role' (Kahn, 1990). Later on, Kahn's model was tested that supported 
the Kahns' findings stating that psychological surroundings of meaningfulness, protection and availability are associated with engagement positively. Whereas, engagement was also defined as an employees positive attitude towards their organization, its values, employees awareness about business and work context through which organizational efficiency and effectiveness can be improved (Robinson, Perryman, \& Hayday, 2004).

Schaufeli et al. (2002) gave another prominent conceptualization of engagement which emerges from a fulfilling, positive, work-related state of mind that is categorized by vigor, absorption and dedication. while working with high levels of mental flexibility and energy is defined by Vigor; also when someone has the willingness and ability to invest effort in his work by showing persistence even during work complications. Having a sense of meaning, eagerness, pride, inspiration and challenge is been defined as dedication.. Whereas; when one remains completely focused and happily engrossed in individual's work, when time flies fast and feel hard to detach him/herself from work (Schaufeli et al., 2002), is the third and constituting element of engagement defined as absorption. Bedarkar and Pandita (2014) wrote that those employees who show following three behaviors, namely Say, Stay and Strive are actually the engaged employees. Employee engagement is although a relatively new concept but is being extensively used and well-liked term in organizational sciences (Robinson et al., 2004). The interest of academicians and practitioners in it is still emerging, and attributed to the claims that the organizations which leverage on employee engagement can witness noteworthy direct impact on desired end results (Macey \& Schneider, 2008; Rana, Ardichvili, \& Tkachenko, 2014), using the top down design approach of the job (Hackman \& Oldham, 1976).

\section{Job Resources and Engagement}

Studies on antecedents and consequences of employee engagement were conducted by different researchers but the first prominent research in the academic literature on it was tested by Saks (2006). In the meta analyses by Bailey et al. (2017), sixty-five i.e. thirty eight (38\%) percent of the studies utilized job demands-resources (JD-R) framework to help explain engagement among which most of the papers also used the UWES. This viewpoint is originated from job characteristics theory by Hackman and Oldham (1976) which illustrates that the desired psychological conditions which are necessary for engagement can be generated from different attributes of work design including task significance, support, autonomy, and feedback. This theory argues that employees who receive both social and economic benefits from within their organization are more likely to return back to their organization in the form of positive and affirmative outcomes. In order to prevail over the limitations of other models on occupational psychology e.g., Job Demands Control Model and Effort Reward Imbalance Model, (Bakker \& Demerouti, 2008) developed the Job demand resources (JDR) model based on the notion that JDR not only focus on the negative aspects of the job but also study and analyze positive aspects of different characteristics of job and its health improving effects ultimately (Bakker \& Demerouti, 2007; De Lange, De Witte, \& Notelaers, 2008). 


\section{Figure 1}

The JD-R work engagement model Bakker and Demerouti (2008)

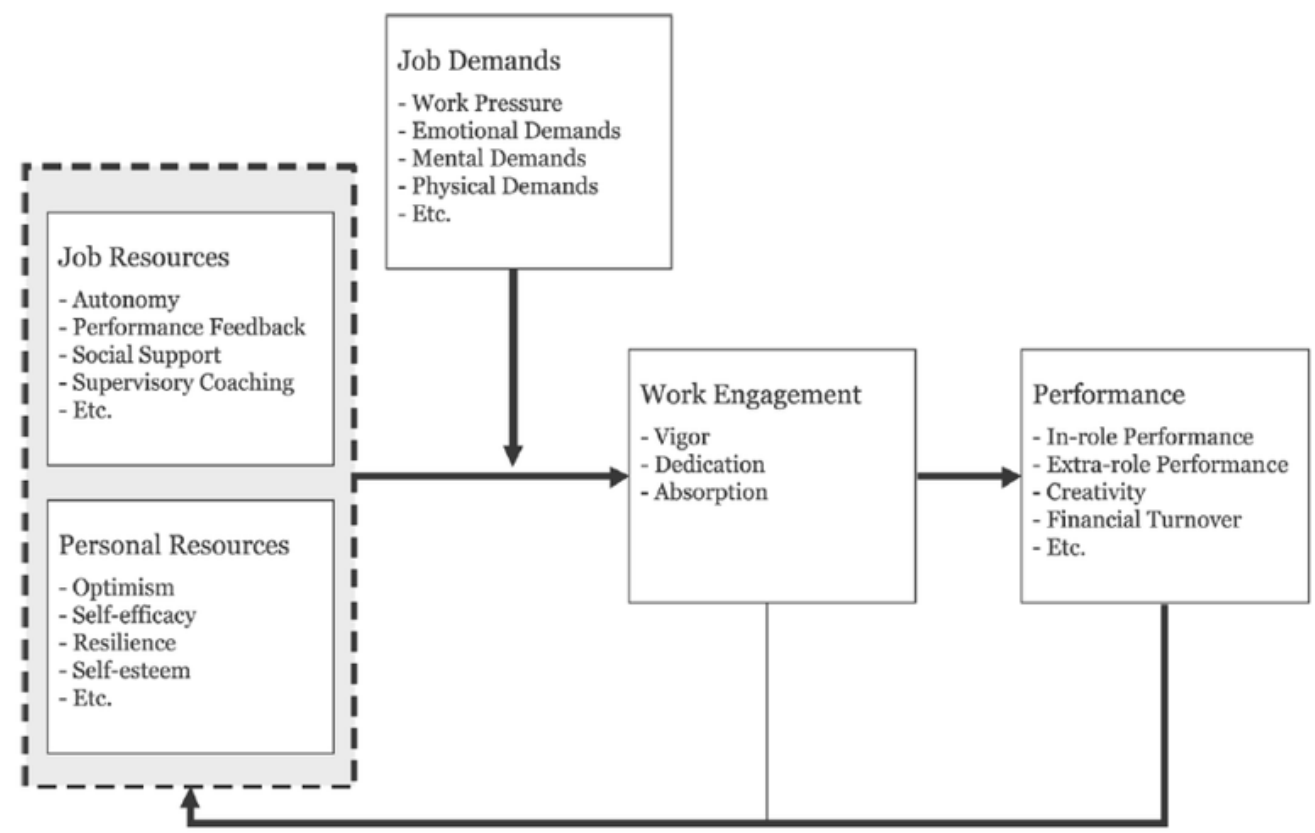

JD-R model concluded by Demerouti, Bakker, Nachreiner, and Schaufeli (2001) categorizing the outcomes of work into two different broad classes including job demands and job resources (See Fig: 1). In this model it was also proposed that any emotional, mental, physical or undue expectations at job from the employee which are the demands of the job actually will lead to raised burnout level among the employees. While job resources as the second broad class of JDR model include, providing support, autonomy, encouraging feedback alleviate the unpleasant effects and helps increase engagement (Bakker \& Demerouti, 2007). Therefore, in a nutshell those employees who experience lack of resources along with high job expectations are more likely to develop high burnout along with decreased engagement at workplace (Schaufeli \& Bakker, 2004). Authors also identified job's design and characteristics along with Human resource development practices as the key drivers of employee engagement in the theoretical models of employee engagement (Rana et al., 2014) as resources not only are vital on its own but also are crucial to help deal with demands of the job (Bakker \& Demerouti, 2007), this notion supports Conservation of resources (COR) theory (Hobfoll, 2001). Job characteristics theory by Hackman and Oldham (1976) emphasizes the motivational prospective of job resources, including feedback, autonomy, support and task significance. Bakker and Demerouti (2007); Sonnentag, Dormann, and Demerouti (2010) supported that resources like, support, autonomy and encouraging feedback not only help mitigate the adverse effects of job demands but rather help improve and turn into the positive outcomes of job like engagement. Xanthopoulou, Bakker, Demerouti, and Schaufeli (2007) used the conservation of resources (COR) theory to support 
that job resources significantly influence engagement through personal resources among school principals and teachers. Hu and Bentler (1999) conducted a longitudinal study over the time to analyze the job demands, job resources and employee well being; reported that those employees under observation who receive less resources exhibited a marked increase in the level of their burnout but a significant decrease in the level of engagement, this idea supported the (Bakker \& Xanthopoulou, 2013) view. Therefore we hypothesized the following:

$H_{1}$ : There is significant impact of workplace autonomy on teachers' engagement.

$\mathrm{H}_{2}$ : There is significant impact of feedback on teachers' engagement.

$H_{3}$ : There is significant impact of supervisor support on teachers' engagement.

\section{Engagement and Performance}

Scholars undeniably agree that, in this century all managers are determined to increase their businesses performance thus demands more efficiency and output than any other period of the history (Mone \& London, 2018; Nazir \& Islam, 2017) for that purpose managers have been striving persistently through many challenges to be successful and leading their company ahead of competitors (Shuck \& Wollard, 2010). Bailey et al. (2017) performed a systematic review of the argument that raised levels of engagement actually augment the performance of the employee and thus organizations; through an extensive review of the narrative literature of conceptual and empirical studies. Similarly, Bedarkar and Pandita (2014) wrote that during any adverse and problematic times employee engagement nowadays is considered as the most crucial and tool of strategic importance to attain competitive advantage. This concept of engagement versus performance is also supported by the JD-R model of work engagement by Bakker and Demerouti (2008) and this notion is also similar to as suggested by David Guest in 1991 claims that the HR manager has specific strategies and practices when executed, will result in behavioral and business outcomes. The existing literature on performance (Williams \& Anderson, 1991; Biswas \& Varma, 2011) suggests in-role and extra-role as two categories of employee performance. The extent to which employee execute his/her requirements of the job description is regarded as Inrole performance (Williams \& Anderson, 1991), whereas all actions other then the formal role requirements are suggested as extra-role performance and are totally at employees prudence (George \& Brief, 1992; Bedarkar \& Pandita, 2014). Furthermore, all policies and practices pertaining to HR in modern-day are deliberated with a approach that not only increases the individuals' involvement for on-the-job requirements but also encourages extra-role behavior of employees (Guest, 1997; Budhwar \& Khatri, 2001; Biswas \& Varma, 2011; Bratton \& Gold, 2017).

Van Wingerden et al. (2017) in their study identified that combined intervention of personal resources and job crafting displayed contributory positive influence on work engagement that resulted in enhanced in-role performance. This finding supports the notion of Bakker and Xanthopoulou (2013) that in order to deal with the work tasks effectively it is vital for the employees to have personal resources in an adequate range which in turn 
improve engagement. In various studies highly engaged teachers not only work harder but were found more innovative in recent studies, does stay longer at jobs (Nazir \& Islam, 2017) and were additionally creative at work (Bakker \& Xanthopoulou, 2013). Teachers while acting as real change agents, help promote the speed of developmental process of our society only if the issue of Teachers' performance is addressed appropriately by the concern authorities (Waseem et al., 2013). Employee engagement is the solution to deal with the shortage problem and gaining retention of good faculty members in the higher educational institutions (Nazir \& Islam, 2017). In spite of that different scholars have shown keen interests in past, exploring the construct employee engagement and identifying its relationships with various outcomes (Saks, 2006; Bakker \& Xanthopoulou, 2013; Bedarkar \& Pandita, 2014; Van Wingerden et al., 2017), however, the prominent empirical studies on the topic specifically within the higher education context are limited (Daniels, 2016; Nazir \& Islam, 2017). The scarcity of studies on the said topic can be detrimental for those organizations which are specifically more dependent on their employees in order to outperform, such as the labor intensive education sector. The current study tries to respond and fill this research gap, by investigating and empirically validating the relationship of employee engagement and employee performance in Pakistani higher educational context. Based on the given arguments following hypotheses are suggested:

$H_{4_{a}}$ : There is a significant impact of employees' engagement on teachers' in-role performance.

$H_{4_{b}}$ : There is a significant impact of employees' engagement on teachers' extra-role performance.

\section{Contribution of this Study}

This study fills in the gap for the need to address the scant literature on the antecedents and outcome of engagement within educational environment, while; work engagement and performance based outcome together has appeared fairly recently in academic research (Mone \& London, 2018). Therefore, this study offers important theoretical contributions to the understanding of the linkage among Job resources, engagement and employees' self rated both In-role and extra-role performances; utilizing the JDR model within educational field. The key Job resources emerged from the systematic review of literature was included in the study to validate it empirically and eventually help boosting engagement within educational environment. The novel finding within specific context of the study was that only supervisor support helps in boosting engagement levels on the contrary increased autonomy and feedback mechanism among faculty members does not have any significant influence on the work engagement. Our study also revealed that with the combine intervention of personal resources on employees engagement level leads to improved both in-role performance and extra-role performances. Therefore, it will help engagement practitioners to identify and promote specific behavioral and thought processes within engaged teachers while designing interventions and engagement strategies. 


\section{Hypothesized Model and Hypotheses}

The given below Figure-2 contains the hypothesized model along with the suggested hypothesized paths. The given paths will be tested empirically in the study:

\section{Figure 2}

Proposed hypothesized model

\section{Job Resources}

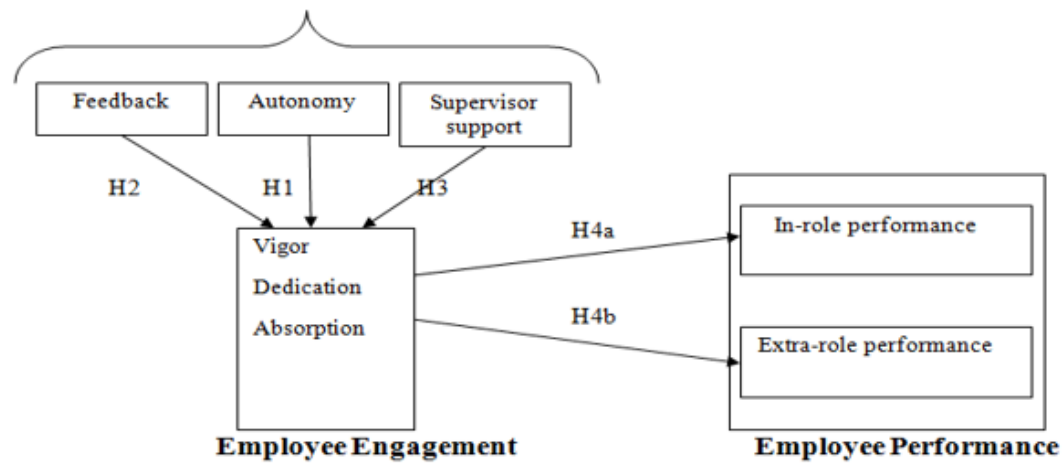

\section{Methodology}

\section{Descriptive Analysis}

The survey measurement tool was distributed among 250 permanent faculty members belonging to business schools of Karachi, from which 208 questionnaires were returned back. After screening of the data, multivariate outliers were detected by using Mahalanobis distance (D2) critical chi-square function at $\mathrm{p}<0.001$, a total of 19 invalid responses, were removed and a final count of 189 responses were deemed usable for further analysis. The collection of sample data using the measurement tool which was written in English took two months (August 2018 to September 2018) by utilizing both hardcopy and online medium. The authors adopted for convenience sampling for data collection, as researchers tend to randomly select from samples of convenience (Tharenou, Donohue, \& Cooper, 2007; Marczyk, DeMatteo, \& Festinger, 2005). The assumptions of SEM were checked in order to carry out the data analysis; including sample size, outliers, normality of the data, scales and multicollinearity issues (Hair, Anderson, Tatham, \& Black, 1998). As per Churchill and Iacobucci (2010) suggested for SEM measurements, yet with a small sample size of 50100 responses SEM models can also perform well. Further, Hair et al. (1998) also suggested that study with 50 to 400 observations is also adequate. Therefore, in our context, the given study sample size is 189 , establishing that in order to perform estimations our sample set would be sufficient. 


\section{Measures}

A survey instrument was prepared so that the hypothesized model can be tested empirically displayed in Fig-2; using the adapted scales from previous published studies. The questionnaire included two factors and 8 variables namely: Employee engagement (UWES Scale)-(Vigor, Dedication and Absorption), Autonomy, Feedback, Supervisor support and employee performance - (In-role \& Extra-role behavior). The original 17 item Utrecht Work Engagement Scale (UWES) was utilized to measure Work Engagement by Schaufeli and Bakker (2004) using seven- point likert scale. Employee Performance Scale established by Lynch, Eisenberger, and Armeli (1999) was adopted to measure Employee performance, which in total comprises of 16 items, out of which in-role behavior measured by nine items, and remaining seven items used to measure extra-role performance behavior. The three items scale by Komaki (1986) consistently utilized to measure Supervisor feedback. The measure of job autonomy was adopted from Ford, Weissbein, and Plamondon (2003) using four survey items. Measures for Supervisor support was adapted from the study of Anderson, Coffey, and Byerly (2002) comprising of six items in total. A 5-point Likert scale was used to answer these questions ranging from (1) for strongly disagree to (5) strongly agree.

\section{Data Analysis}

Two statistical softwares SPSS 21 and AMOS 21 were utilized for carrying data analysis with a sample of $\mathrm{N}=189$. By recognizing the (Hair et al., 1998) rule if value of Karl Pearsons correlation is $>0.90$ identifies that the issue of multicollinearity exists in the study, values in Table- 1 shows that there is no issue of multicollinearity as highest value is 0.486 between Feedback and Supervisor support (Hair et al., 1998; Lin \& Lee, 2004). Nunally and Bernstein (1978) suggested to check the reliability of the instrument the Cronbach $\alpha$ value should be more than 0.6 , hence in our study after removing 2 items of Supervisor support, 1 item of Feedback and 4 items from in-role employee behavior, all Cronbach alpha values of variables were greater than 0.6 (See Table-1).

Table 1

Mean, Standard Deviations and Correlations (N=189)

\begin{tabular}{lccccccc}
\hline & Mean & Std. Deviation & SS & FB & AUT & EE & EPIR \\
\hline SS & 3.7411 & 1.1003 & $(0.820)^{* * *}$ & & & \\
FB & 3.7777 & 0.91941 & $.486^{* *}$ & $(0.6720)^{* * *}$ & & & \\
AUT & 3.7085 & 0.91272 & $.312^{* *}$ & $.324^{* *}$ & $(0.719)^{* * *}$ & & \\
EE & 4.2435 & 0.96285 & 0.112 & 0.099 & $.321^{* *}$ & $(0.860)^{* * *}$ & \\
EPIR & 4.1564 & 0.98317 & $.147^{*}$ & $.162^{*}$ & $.139^{*}$ & $.184^{* *}$ & $(0.685)^{* * *}$ \\
EPER & 3.7944 & 0.8638 & 0.111 & 0.111 & 0.100 & $.179^{* *}$ & $.391^{* *}$ \\
\hline$* * *$
\end{tabular}

*** Values in parenthesis shows Cronbach alpha values

$* *$. Correlation is significant at the 0.01 level (2-tailed).

* Correlation is significant at the 0.05 level (2-tailed). 


\section{Internal Reliability and Validity of Constructs}

Estimation of different indices indicates the fitness of the Measurement model. Measuring validity and reliability ensures the fitness of the instrument and its results, similarly convergent validity ensures that the items from the instrument highly correlates with the specific variable with which it should correlate theoretically. The results of Cronbach alpha $(\mathrm{C} \alpha)$, composite reliability $(\mathrm{CR})$ and average variance explained (AVE) are given in Table-2, establishing the construct and convergent validity. In the current study for all included variables Cronbach alpha values were found more than the threshold value of 0.6 (Nunally \& Bernstein, 1978). Composite reliability being a more appropriate indicator for construct validity (Lin \& Lee, 2004) was also used to measure the reliability of the overall scale being used. Based on the suggested criterion for ensuring CR (above 0.7) and AVE (above 0.5) implies the scale as reliable and valid (Bagozzi \& Yi, 1988), therefore, data results identifies and accepted in terms of reliability and convergent validity as all the variables surpassed the threshold values, also the composite reliability for feedback is slightly less than threshold of 0.7 that is 0.676 ; but as per Hair et al., a CR value between 0.6 to 0.7 would be sufficient if a models construct validity is good with factor loadings greater than 0.5. So it was concluded in this study no serious issue of validity existed, therefore the data and constructs can be carried further (Bouwman, Carlsson, Molina-Castillo, \& Walden, 2007; Waseem et al., 2016; Voorhees, Brady, Calantone, \& Ramirez, 2016).

\begin{tabular}{|c|c|c|c|c|}
\hline Variables & $\begin{array}{l}\text { Final (33) items } \\
\text { extracted in CFA }\end{array}$ & $C R^{a}$ & $A V E^{b}$ & CronbachAlpha \\
\hline SS & 4 & 0.818 & 0.531 & 0.820 \\
\hline $\mathrm{FB}$ & 2 & 0.676 & 0.511 & 0.672 \\
\hline AUT & 2 & 0.847 & 0.740 & 0.719 \\
\hline $\mathrm{EE}$ & 16 & 0.899 & 0.574 & 0.860 \\
\hline EPIR & 5 & 0.794 & 0.759 & 0.685 \\
\hline EPER & 4 & 0.832 & 0.555 & 0.604 \\
\hline $\begin{array}{l}\text { Source: } \mathrm{Au} \\
\mathrm{a}: \mathrm{CR}>0.7 \\
\mathrm{~b}: \mathrm{AVE}>0 . \\
\text { c: Cronbacl }\end{array}$ & $\begin{array}{l}\text { Mors Estimation }(\mathrm{N}=1 \\
\text { Bagozzi and } \mathrm{Yi}(1988) \\
\text { Bagozzi and } \mathrm{Yi}(198 \\
>0.6 \text { Nunally and B }\end{array}$ & nstei & 978) & \\
\hline
\end{tabular}

\section{Common Method Variance}

CFA was performed in the present research with thirty three (33) final loaded items that signify six factors that are, employee engagement (EE), feedback (FB), autonomy (AUT), supervisor support (SS), in-role performance (EPIR) and extra-role performance (EPER) of employees. The CFA model as per Byrne (2013) identifies the relationship between latent variables and measured items. Results of the convergent validity are given in Table 2 including final extracted items, composite reliability (CR) and average variance explained (AVE), as the recommended threshold were met the constructs were carried forward for conceptual analyses. The CFA model fitness relies on estimation different model fit indices for its efficiency. The literature for that purpose supports on not to rely on reporting 
any single index, a combination of indices for measuring the fitness of the model shall be reported (Crowley \& Fan, 1997).

A combination of Chi-Square test with CFI, RMSEA and SRMR was strongly supported by Kline (1999), for Chi-Square (Tabachnick, Fidell, \& Ullman, 2007) recommended the threshold value of less than 2, the CFI shall be more than 0.90 (Hu \& Bentler, 1999; Byrne, 1994); the Root Mean Square Error of Approximation (RMSEA) as proposed by Browne et al. (1993) shall be $\leq 0.05$ and the Standardized Root Mean square Residual (SRMR) shall be $<0.08$ (Hu \& Bentler, 1999). The authors has utilized the suggestion by McDonald and Ho (2002) according to which Comparative Fit index (CFI) are the most commonly reported stated model fitness indice. As these indices are highly insensitive to sample size, any misleading or the parameter estimates are preferred over other indices, so therefore following the recommendation by Kline (1999), for measurement of Goodness of fit Table 3 presents the values of indices for four different comparative models along with the final hypothesized model.

Table 3

Summary of Model Comparisons ( $\mathrm{N}=189)$

\begin{tabular}{|c|c|c|c|c|}
\hline Recommended value & $<2.0$ & $>0.90$ & $\leq 0.05(>0.5)$ & $<0.08$ \\
\hline Source & Tabachnik and Fidell (2007) & $\mathrm{Hu}$ and Bentler (1999) & Browne et al.(1993) & $\mathrm{Hu}$ and Bentler (1999) \\
\hline Null Model a & 2.841 & 0.455 & $0.099(0.000)$ & 0.103 \\
\hline Two Factor Model b & 3.373 & 0.458 & $0.098(0.000)$ & 0.113 \\
\hline Three Factor Model c & 2.826 & 0.583 & $0.086(0.000)$ & 0.097 \\
\hline Hypothesized Model d (33 items) & 1.336 & 0.944 & $0.042(0.928)$ & 0.054 \\
\hline SEM & 1.512 & 0.912 & $0.050(0.921)$ & 0.082 \\
\hline
\end{tabular}

Source: Authors Estimation

a. Null model $=46$ items

b. A Two Factor Model = Factor 1(30 Employee engagement \& its drivers items), Factor 2(16 Employee performance items)

c. A Three factor Model = Factor 1 (17 items of Employee engagement), Factor 2 (Drivers of Engagement-13 items) and Factor 3

(16 Employee performance items)

d. Hypothesized Model composed of Factor 1 (16 items of Employee engagement), Factor 2 (4 items of supervisor support), Factor 3

( 2 items of Feedback), Factor 4 ( 2 items of Autonomy), Factor 5 ( 5 items of Employee inrole behavior) and Factor 6 ( 4 items of Employee Extrarole behavior)

As shown in above table; the fit indices values suggest our data fits well in the measurement model thus confirming to the existing theories and validating the constructs. As shown in Table-3 the CMIN/DF value of our final CFA model is calculated as 1.336, CFI value is calculated as 0.944 , RMSEA value is measured to be 0.042 and SRMR is calculated as 0.0544 which satisfied all recommended threshold prescribed by various authors. In the final measurement many error terms has been incorporated but only within a factor and not among different factors, as in our measurement model the correlation among error terms has been applied in the way that previously accepted and suggested by various researchers (Byrne, Shavelson, \& Muthén, 1989). Although, the results of our final model reflect the best fitness and efficiency of model; but the previous studies emphasize that good fitness models can also have misspecification (Armenakis, Bernerth, Pitts, \& Walker, 2007). Therefore to deal with the issue it is recommended to compare alternate models' fitness results with the hypothesized model (Mulaik et al., 1989; Armenakis et al., 2007). Based on the recommendation, in this study our final measurement model was compared with three competing models and the results of this comparison are displayed in Table-3 identifying the superiority of our hypothesized model. 


\section{Structural Equation Modeling}

The present study was tested by structural equation modeling (SEM) in order to validate the theoretical framework and test the hypothesis constructed for the study. Byrne (2013) suggested the structural model investigates the relationship among latent variables. The results of our hypothesized structural model are displayed in Table 3 which ensures the good fit and efficiency of our model evaluated by the value of normed chi-square (CMIN/DF) $=1.512$ significantly lower than the Byrne (2013)'s recommended value of 5, also than the recommended value of 2 by Tabachnick et al. (2007); CFI $=0.912$; and RMSEA $=0.050$ $(\mathrm{PCLOSE}=0.921)$. The recommended values reported for different fit indices have been exceeded for the current study data and therefore our model exhibit good fitness.

Figure 3

The Structural Model Results [Note: $\left.{ }^{*} \mathrm{p}<0.10 ;{ }^{* *} \mathrm{p}<0.05 ;{ }^{* * *} \mathrm{p}<0.01\right]$

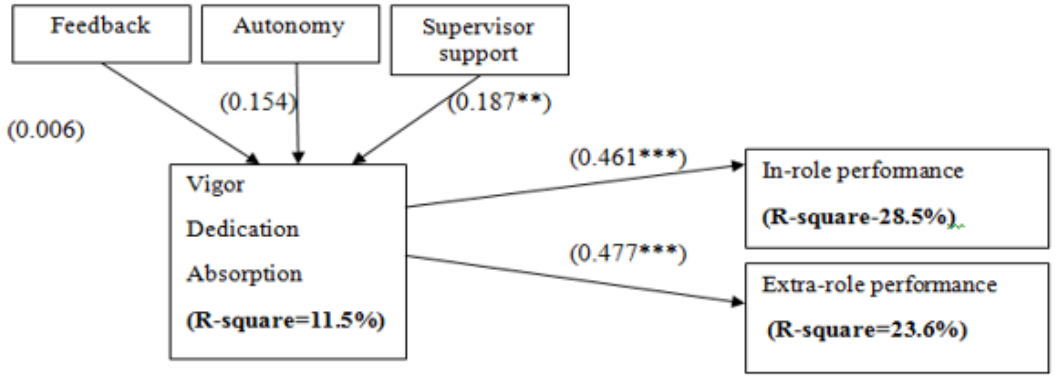

Employee Engagement

Employee Performance

Table 4

SEM Hypothesis Testing

\begin{tabular}{|c|c|c|c|c|c|c|c|c|}
\hline Hypothesis & Hypot & hesized & Path & Path Coefficient & S.E. & C.R. & P-value & Remarks \\
\hline $\mathrm{H} 1$ & $\mathrm{EE}$ & $<-$ & AUT & 0.154 & 0.082 & 1.885 & 0.059 & Not supported \\
\hline $\mathrm{H} 2$ & $\mathrm{EE}$ & $<-$ & FB & 0.006 & 0.099 & 0.061 & 0.952 & Not supported \\
\hline H3 & $\mathrm{EE}$ & $<-$ & SS & 0.187 & 0.08 & 2.348 & 0.019 & Supported \\
\hline $\mathrm{H} 4 \mathrm{a}$ & EPIR & $<-$ & $\mathrm{EE}$ & 0.461 & 0.099 & 4.656 & $* * *$ & Supported \\
\hline $\mathrm{H} 4 \mathrm{~b}$ & EPER & $<-$ & $\mathrm{EE}$ & 0.477 & 0.103 & 4.613 & $* * *$ & Supported \\
\hline \multicolumn{9}{|c|}{ Squared Multiple correlations(R-square) } \\
\hline \multicolumn{9}{|c|}{ EE $\quad 11.50 \%$} \\
\hline & EPIR & \multicolumn{7}{|l|}{28.5} \\
\hline & EPER & \multicolumn{7}{|l|}{$23.60 \%$} \\
\hline
\end{tabular}

The statistical significance of determinants and outcome for employee engagement were all tested for their hypotheses given in the study and confirm the validity. Table 4 shows the results of SEM regression paths, standardized regression weights, standard errors, critical ratios, probability values and concluding remarks of the hypothesis. The results suggested the non-significant impact of two drivers of engagement i.e. feedback $(\mathrm{FB})$ and Autonomy (AUT) on faculty's engagement at workplace. Whereas, Supervisory support as 
an important job resource do have a significant impact $(\beta=0.187, \mathrm{p}=0.019)$, on faculty's engagement. Further, it is also statistically supported that employees engagement (EE) do have a significant positive influence on the employees in-role $\left(\beta=0.461, \mathrm{p}^{* * *}\right)$, and extra-role work performances $\left(\beta=0.477, \mathrm{p}^{* * *}\right)$.

Among three endogenous variables, employees In role work performance behavior (EPIR) is most vital construct in explaining the engagement model. EPIR explains $28.5 \%$ and EPER explains $23.6 \%$ of the variation in engagement model. When engagement (EE) is raised by one standardized unit, EPIR is enhanced by 0.461 and EPER by 0.477 standardized units. Moreover, confirming the hypothesis H4a and H4b. In total the present study contains the five formulated hypotheses, out of which three are statistically found significant from our analysis of the data. Displayed in Figure 3 are the empirical findings of our research hypotheses.

\section{Discussion and Managerial Implications}

This study has significant implications for theory and management practices as it had promoted the research on EE by including its possible antecedents and consequences, also clearly conceptualizing the term; thus can have important influences on the managers of the organizations while decision making on EE strategies.

Bailey (2017) in a meta analyses has identified that many different job resources have been studied along with engagement, which includes support from supervisor, peer support, feedback, autonomy and others. In almost all of the studies the results have shown some degree of positive connection between job resources and engagement, while a study by Ouweneel et al. (2012) was an exception, in which it was found non-significant association between the variables under study. Also, in our study only one job resource supervisor support is found to have positive and significant influence on engagement. Although the notion resources have a significant impact on work engagement was also assumed in JDR model (Schaufeli \& Bakker, 2004) like previously proven in past study by Xanthopoulou et al. (2007), but the present study highlights the fact individuals own personality, his/her personal resources or other individual factors play a more dominant role rather than the job resources while predicting work engagement (Albrecht \& Marty, 2017), such as; those teachers with high confidence in their abilities i.e. personal resource will most likely are at ease to ask for or receive performance feedback (job resource) from their department head or students because of their confidence of handling this feedback, the same is argued by (Van Wingerden et al., 2017). It is not to conclude that work resources or environment is not vital in predicting employees' work engagement behavior; however, we conclude that taking individual factors into account is essential as well. Still it must be considered too; that different policies or nature of industry have different effects, thus yield vast implications for theory building and practices, which future research will need to address. It is also assumed within Pakistani cultural context more an employee gets the autonomy to perform at work, due to freedom of work with less monitoring available it may result in less dedication, thus suggesting controlling factors to be included in future EE researches which can have important future implications for EE practitioners while formulating their EE strategies. 
By adopting diverse theoretical perspectives to help explain the influence of HR practices on employee performances has been vastly studied by scholars. Bailey in 2017 examined various studies for performance outcomes of engagement and concluded it can be categorized under two main sub-headings, the first one as higher level performance outcomes and second as individual performance outcomes. The existing literature by Williams and Anderson (1991) on performance already suggested two forms of work performancein-role and extra-role. However, only few studies have investigated together the role of job resources in improving in-role and extra-role performance of employee by fostering employee engagement (Guan \& Frenkel, 2018), supporting the JD-R model assumption which suggests that by optimizing job demands and job or and personal resources work engagement and performance can be facilitated and fostered (Bakker \& Xanthopoulou, 2013; Demerouti et al., 2001). The argument postulated from JD-R model strengthen the results of our study where the suggested hypothesis that employee engagement have a significant and positive influence an employee's in-role and extra-role performance, and thus this hypothesis was accepted as found to be true. The study is unique as it tried to fill the scarcity of significant empirical research on the topic of engagement as a mechanism to link it with employee performances. The majority of previous researchers used cross-sectional, self- report methods on the topic (Bailey et al., 2017), therefore it is recommended to use complex methods or time-lagged research designs in future researches. It has been reported in 2005 that majority of the American workers were found 'disengaged' which is referred to as 'engagement gap' is annually costing $\$ 300$ billion in lost of productivity, although such type of databases are not available in Pakistan but disengagement problems has been witnessed here too.

As the present study has incorporated modern theoretical models it sheds light on the extant literature of employee engagement and thus academia can be benefited by channelizing their efforts by focusing on those aspects that can help foster the engagement level of faculty members. It is recommended to focus on retaining recruited and developed staff as it is difficult to replace the knowledge and experience of skilled staff, so that a continuous cycle of teaching and excellence in research can be maintained in higher educational institutions (Simmons et al., 2002; Nazir \& Islam, 2017). Employee engagement requires continued interactions with the employer to create a state of reciprocal interdependence as it is an on-going and a long-term process between the two parties (Cropanzano \& Mitchell, 2005) and realizing this fact is crucial for the management of educational institutions. Thus; an engaged and committed workforce in a higher educational institute will have positive and great implications for the society (Nazir \& Islam, 2017). The result of this study is considered to have implications for both the engagement and performance literatures, and for HR practitioners. Therefore it is expected that this study will broaden the scarce literature on engagement and performance especially within the context of Pakistani higher education context.

\section{Limitations and Future Research Recommendations}

The research is cross-sectional; thus, any inferences regarding causality are limited. Yet, based on strong theoretical reasoning to presume causal ordering, also reflected later on 
in the statistical analysis Cross-sectional data was gathered for this research survey from different higher educational institutions of Karachi, Pakistan. Thus, the study can be carried in other geographical regions of Pakistan in order to corroborate the results of the findings. Furthermore, avenues for further research in other sectors also opens where engagement practices actually leads to better performance outcomes such as from medical practitioners thus validating the results in different contexts.

Also, while this study found that two out of three job resources had a weak and insignificant influence on employees engagement; it may also be attempted in future researches to explore some other drivers of engagement such as individual factors as discussed above like monitoring and control factors i.e. style of leadership or type of personalities as predictors of engagement. It is also suggested to design and implement real engagement practices in institutions, observe significant changes over time and then validate the outcomes of engagement thus recommending longitudinal researches, which can be productive for practitioners in academia as well as for researcher 


\section{References}

Albrecht, S. L., \& Marty, A. (2017). Personality, self-efficacy and job resources and their associations with employee engagement, affective commitment and turnover intentions. The International Journal of Human Resource Management, 1-25.

Anderson, S. E., Coffey, B. S., \& Byerly, R. T. (2002). Formal organizational initiatives and informal workplace practices: Links to work-family conflict and job-related outcomes. Journal of Management, 28(6), 787-810.

Armenakis, A. A., Bernerth, J. B., Pitts, J. P., \& Walker, H. J. (2007). Organizational change recipients' beliefs scale: Development of an assessment instrument. The Journal of Applied Behavioral Science, 43(4), 481-505.

Bagozzi, R. P., \& Yi, Y. (1988). On the evaluation of structural equation models. Journal of the Academy of Marketing Science, 16(1), 74-94.

Bailey, C., Madden, A., Alfes, K., \& Fletcher, L. (2017). The meaning, antecedents and outcomes of employee engagement: A narrative synthesis. International Journal of Management Reviews, 19(1), 31-53.

Bakker, A. B., \& Demerouti, E. (2007). The job demands-resources model: State of the art. Journal of Managerial Psychology, 22(3), 309-328.

Bakker, A. B., \& Demerouti, E. (2008). Towards a model of work engagement. Career Development International, 13(3), 209-223.

Bakker, A. B., \& Xanthopoulou, D. (2013). Creativity and charisma among female leaders: The role of resources and work engagement. The International Journal of Human Resource Management, 24(14), 2760-2779.

Bedarkar, M., \& Pandita, D. (2014). A study on the drivers of employee engagement impacting employee performance. Procedia-Social and Behavioral Sciences, 133, 106115 .

Biswas, S., \& Varma, A. (2011). Antecedents of employee performance and the role of job satisfaction as a mediator. Employee Relations, 177-192.

Bouwman, H., Carlsson, C., Molina-Castillo, F. J., \& Walden, P. (2007). Barriers and drivers in the adoption of current and future mobile services in Finland. Telematics and Informatics, 24 (2), 145-160.

Bratton, J., \& Gold, J. (2017). Human resource management: Theory and practice. United Kingdom: Palgrave.

Budhwar, P. S., \& Khatri, N. (2001). A comparative study of HR practices in Britain and India. International Journal of Human Resource Management, 12(5), 800-826.

Byrne, B. M. (1994). Structural equation modeling with EQS and EQS/Windows: Basic concepts, applications, and programming. United Kingdom: Sage.

Byrne, B. M. (2013). Structural equation modeling with Mplus: Basic concepts, applications, and programming. United Kingdom: Routledge.

Byrne, B. M., Shavelson, R. J., \& Muthén, B. (1989). Testing for the equivalence of factor covariance and mean structures: The issue of partial measurement invariance. Psychological Bulletin, 105(3), 456-468.

Cappelli, P., \& Keller, J. (2017). The historical context of talent management. The Oxford Handbook of Talent Management, 23-42. 
Churchill, G. A., \& Iacobucci, D. (2010). Marketing research methodological foundationsinternational edition. Hampshire: South-Western Cengage Learning.

Crawford, E. R., Rich, B. L., Buckman, B., \& Bergeron, J. (2013). The antecedents and drivers of employee engagement. In Employee engagement in theory and practice (pp. 71-95). Routledge.

Cropanzano, R., \& Mitchell, M. S. (2005). Social exchange theory: An interdisciplinary review. Journal of Management, 31(6), 874-900.

Crowley, S. L., \& Fan, X. (1997). Structural equation modeling: Basic concepts and applications in personality assessment research. Journal of Personality Assessment, $68(3), 508-531$.

Daniels, J. R. (2016). An exploratory comparative case study of employee engagement in christian higher education. Christian Higher Education, 15(3), 126-139.

De Lange, A. H., De Witte, H., \& Notelaers, G. (2008). Should i stay or should i go? Examining longitudinal relations among job resources and work engagement for stayers versus movers. Work \&5 Stress, 22(3), 201-223.

Demerouti, E., Bakker, A. B., Nachreiner, F., \& Schaufeli, W. B. (2001). The job demandsresources model of burnout. Journal of Applied Psychology, 86(3), 499-512.

Ford, J. K., Weissbein, D. A., \& Plamondon, K. E. (2003). Distinguishing organizational from strategy commitment: Linking officers' commitment to community policing to job behaviors and satisfaction. Justice Quarterly, 20(1), 159-185.

Frooghi, R., \& andSyeda NazneenWaseem, S. A. (2016). The integration of loyalty, satisfaction, and relationship commitment models to predict customer retention in Pakistani telecom sector. South Asian Journal of Management, 10(2), 56-79.

George, J. M., \& Brief, A. P. (1992). Feeling good-doing good: A conceptual analysis of the mood at work-organizational spontaneity relationship. Psychological Bulletin, 112(2), 310-329.

Guan, X., \& Frenkel, S. (2018). How HR practice, work engagement and job crafting influence employee performance. Chinese Management Studies, 12(3), 591-607.

Guest, D. E. (1997). Human resource management and performance: A review and research agenda. International Journal of Human Resource Management, 8(3), 263-276.

Hackman, J. R., \& Oldham, G. R. (1976). Motivation through the design of work: Test of a theory. Organizational Behavior and Human Performance, 16 (2), 250-279.

Hair, J., Anderson, R., Tatham, R., \& Black, W. (1998). Multivariate data analysis. Prentice-Hall, New Jersey.

Hallberg, U. E., \& Schaufeli, W. B. (2006). "Same same" but different? can work engagement be discriminated from job involvement and organizational commitment? European Psychologist, 11(2), 119-127.

Hobfoll, S. E. (2001). The influence of culture, community, and the nested-self in the stress process: advancing conservation of resources theory. Applied Psychology, 50(3), 337421.

Hu, L.-t., \& Bentler, P. M. (1999). Cutoff criteria for fit indexes in covariance structure analysis: Conventional criteria versus new alternatives. Structural Equation Modeling: A Multidisciplinary Journal, 6(1), 1-55. 
Kahn, W. A. (1990). Psychological conditions of personal engagement and disengagement at work. Academy of Management Journal, 33(4), 692-724.

Kline, R. B. (1999). Book review: Psychometric theory. Journal of Psychoeducational Assessment, $17(3), 275-280$.

Lin, H.-F., \& Lee, G.-G. (2004). Perceptions of senior managers toward knowledge-sharing behaviour. Management Decision, 42(1), 108-125.

Lynch, P. D., Eisenberger, R., \& Armeli, S. (1999). Perceived organizational support: Inferior versus superior performance by wary employees. Journal of Applied Psychology, $84(4), 467$.

Macey, W. H., \& Schneider, B. (2008). Engaged in engagement: We are delighted we did it. Industrial and Organizational Psychology, 1(1), 76-83.

Marczyk, G., DeMatteo, D., \& Festinger, D. (2005). Essentials of research design and methodology. John Wiley \& Sons Inc.

McDonald, R. P., \& Ho, M.-H. R. (2002). Principles and practice in reporting structural equation analyses. Psychological Methods, 7(1), 64-82.

Mone, E. M., \& London, M. (2018). Employee engagement through effective performance management: A practical guide for managers. United Kingdom: Routledge.

Mulaik, S. A., James, L. R., Van Alstine, J., Bennett, N., Lind, S., \& Stilwell, C. D. (1989). Evaluation of goodness-of-fit indices for structural equation models. Psychological Bulletin, $105(3)$, 430-445.

Nazir, O., \& Islam, J. U. (2017). Enhancing organizational commitment and employee performance through employee engagement: An empirical check. South Asian Journal of Business Studies, 6(1), 98-114.

Nunally, J. C., \& Bernstein, I. H. (1978). Psychometric theory. New York: McGraw-Hill.

Parakhina, V., Godina, O., Boris, O., \& Ushvitsky, L. (2017). Strategic management in universities as a factor of their global competitiveness. International Journal of Educational Management, 31(1), 62-75.

Rana, S., Ardichvili, A., \& Tkachenko, O. (2014). A theoretical model of the antecedents and outcomes of employee engagement: Dubin's method. Journal of Workplace Learning, 26(3/4), 249-266.

Robinson, D., Perryman, S., \& Hayday, S. (2004). The drivers of employee engagement. Report-Institute for Employment Studies. Retrieved from tinyurl.com/ IES-drivers

Saks, A. M. (2006). Antecedents and consequences of employee engagement. Journal of Managerial Psychology, 21(7), 600-619.

Schaufeli, W. B., \& Bakker, A. B. (2004). Job demands, job resources, and their relationship with burnout and engagement: A multi-sample study. Journal of Organizational Behavior: The International Journal of Industrial, Occupational and Organizational Psychology and Behavior, 25(3), 293-315.

Schaufeli, W. B., Salanova, M., González-Romá, V., \& Bakker, A. B. (2002). The measurement of engagement and burnout: A two sample confirmatory factor analytic approach. Journal of Happiness Studies, 3(1), 71-92.

Shuck, B., \& Wollard, K. (2010). Employee engagement and HRD: A seminal review of the foundations. Human Resource Development Review, 9(1), 89-110. 
Simmons, D. C., Kame'enui, E. J., Good, R., Harn, B. A., Cole, C., \& Braun, D. (2002). Building, implementing, and sustaining a beginning reading improvement model: Lessons learned school by school. Interventions for Academic and Behavior Problems II: Preventive and Remedial Approaches, 537-570.

Sonnentag, S., Dormann, C., \& Demerouti, E. (2010). Not all days are created equal: The concept of state work engagement. New York: Psychology Press.

Storm, K., \& Rothmann, S. (2003). A psychometric analysis of the utrecht work engagement scale in the South African police service. SA Journal of Industrial Psychology, 29(4), 62-70.

Tabachnick, B. G., Fidell, L. S., \& Ullman, J. B. (2007). Using multivariate statistics. Boston, MA: Pearson.

Tharenou, P., Donohue, R., \& Cooper, B. (2007). Management research methods. Cambridge University Press.

Van Wingerden, J., Derks, D., \& Bakker, A. B. (2017). The impact of personal resources and job crafting interventions on work engagement and performance. Human Resource Management, 56(1), 51-67.

Voorhees, C. M., Brady, M. K., Calantone, R., \& Ramirez, E. (2016). Discriminant validity testing in marketing: An analysis, causes for concern, and proposed remedies. Journal of the Academy of Marketing Science, 44(1), 119-134.

Waseem, S. N., Frooghi, R., \& Afshan, S. (2013). Impact of human resource management practices on teachers' performance: A mediating role of monitoring practices. Journal of Education and Social Sciences, 1(2), 31-55.

Waseem, S. N., Frooghi, R., \& Khan, B. S. (2016). Empirical assessment of the constructs: Workplace engagement, job burnout and turnover intention. Journal of Education $\&$ Social Sciences, 4(2), 112-131.

Williams, L. J., \& Anderson, S. E. (1991). Job satisfaction and organizational commitment as predictors of organizational citizenship and in-role behaviors. Journal of Management, 17(3), 601-617.

Xanthopoulou, D., Bakker, A. B., Demerouti, E., \& Schaufeli, W. B. (2007). The role of personal resources in the job demands-resources model. International Journal of Stress Management, $14(2), 121-141$.

Yadav, A., \& Katiyar, D. (2017). Workforce diversity and individual differences: Implications for employee engagement. Indian Journal of Commerce and Management Studies, 8(3), 7.

Yalabik, Z. Y., Popaitoon, P., Chowne, J. A., \& Rayton, B. A. (2013). Work engagement as a mediator between employee attitudes and outcomes. The International Journal of Human Resource Management, 24(14), 2799-2823. 